\title{
Empowering Families Through Research-Based Museum Exhibits on Child Development: Impacts on Parents and Implications for Researcher- Museum Partnerships
}

\author{
Laura E. Michaelson ${ }^{1}$, Jesse C. Niebaum², Sarah Brenkert ${ }^{3}$, Grace L. Dostart ${ }^{4}, \&$ Yuko Munakata ${ }^{2}$ \\ ${ }^{1}$ American Institutes for Research, Arlington, Virginia. ${ }^{2}$ Department of Psychology and Center for Mind \\ and Brain, University of California, Davis. ${ }^{3}$ Seattle Aquarium, Seattle, Washington. ${ }^{4}$ Renee Crown \\ Wellness Institute, University of Colorado Boulder
}

This is a preprint of a manuscript currently under review. The data and analysis code for this manuscript can be found on the project's Open Science Framework Page (osf.io/yqdfe/).

Version Date: August 25, 2021

\section{Acknowledgements}

The authors would like to the University of Colorado Boulder's Office of Outreach and Engagement and the National Living Lab for funding, the participating families at the Children's Museum of Denver at Marsico Campus, the museum staff, particularly Erika Weiss, Susan Lynds for consultation about the survey, and the interns who staffed the research exhibit: Monique Baca, Kathryn Flint, Willow Hagan, Micaela Hines, Kale Huber, Sydney Krieg, Taylor Mitchell, Hayden Morano, Arielle Sandoval, Shadi Sharif, Lexi Thomson, Abigail Tracer, and Kaylyn Van Deusen. 


\begin{abstract}
Increased recognition of the need to study child development in more naturalistic contexts has led to the formation of partnerships between researchers and museums. Researchermuseum partnerships provide researchers access to families and more naturalistic contexts within which to study child development. Although benefits for researchers are well established, benefits for the museum or visitors are less clear. To investigate potential benefits of research exhibits for parents, we compared the impact of a research toy exhibit and permanent museum exhibits at a children's museum. Although parents reported that their children had less fun at the research exhibit, parents learned more at the research exhibit and reported that the research exhibit raised more questions and had greater relevance to them compared with permanent exhibits. Parents were also more likely to apply ideas from the research exhibit into their daily life compared with permanent exhibits. Our findings support unique benefits for research exhibits for parents and indicate a need to showcase potential learning opportunities for visitors in future research-museum partnerships.
\end{abstract}




\section{Introduction}

Interest in the science of child development has increased dramatically in recent decades. At the same time, research on child development has broadened focus from the individual child to the child in naturalistic contexts (Bronfenbrenner, 1977; Rogoff, 2003). In museums, children engage in learning and reasoning about materials, tools, and scientific concepts. Museums can also facilitate spontaneous peer and family interactions, making the museum context more naturalistic and child-driven for studying development than the lab or school (Henderson \& Atencio, 2007; Tõugu et al., 2017). For example, observations and manipulations of the style of family interactions during museum visits have shown how family conversations contribute to children's learning and development (Callanan et al., 2020; Callanan \& Valle, 2008; Chandler-Campbell et al., 2020; Gelman et al., 1998; Willard et al., 2019). Thus, museums provide an important window into experiences and interactions that shape children's learning and development that are not easily observed or constructed by researchers.

In response to the growing recognition of the unique research opportunities afforded at museums, developmental scientists are forming partnerships with children's museums to conduct research on child development (Beaumont et al., 2016; Callanan, 2012; Corriveau et al., 2015; Sobel \& Jipson, 2015). Partnerships provide clear and direct benefits to researchers and science. Museums provide access to families and a rich source of contexts within which to study child development (e.g., Benjamin et al., 2010; Letourneau et al., 2017; Song et al., 2012). Researchers gain experience with conducting field research and communicating with lay audiences, including museum staff (Williams \& Sparks, 2011). Studying children in museums also allows researchers to map development across a wide age span and establish norms with large and diverse samples (Frank et al., 2012).

In contrast, direct benefits to museums and parents, and the immediacy of such benefits, may be less clear. Research partnerships bring developmental scientists into museums; these scientists can engage families and museum staff to discuss findings on child development with individuals who could most benefit. Prior research on research-museum partnerships showed that parents of children who participated in a research exhibit reported positive experiences, that they learned something new, and found the research to be relevant to their own lives and the museum experience (Lussenhop et al., 2013, 2016). However, this feedback may have been driven by demand characteristics, given that participating families were recruited by indicating a desire to provide museum feedback and that interviews were conducted in person with museum staff and the researchers. Moreover, parents were only 
asked about research exhibits (Lussenhop et al., 2013), so it remains unclear whether such exhibits provide unique benefits relative to permanent museum exhibits.

The goals of the present study were to identify benefits of research exhibits for parents and to test whether such benefits are unique relative to those of permanent museum exhibits. We adapted an exhibit developed for the National Living Lab Initiative (livinglab.org; Beaumont et al., 2016), in which staff and parents encourage children to complete a puzzle building activity while researchers communicate findings on child praise with parents (Mueller \& Dweck, 1998). We surveyed parents on their experiences with the museum, the research exhibit, and a permanent museum exhibit. Importantly, parents completed the survey online and after their museum visit to minimize participants demand characteristics and support more honest reporting. We hypothesized that research exhibits stimulate parents' interest in the science of child development and that parents find such exhibits to be uniquely relevant to their daily lives compared with permanent museum exhibits. If so, this would provide the evidence for direct benefits of research-museum partnerships to museums and their visitors.

\section{Methods}

\section{Sample}

Data collection spanned 16 months (November 2016 - March 2018). Table 1 provides demographic characteristics of the respondents. Respondents were primarily female (84\%), White (85\%), and high-income, with the majority making over $\$ 70,000$ per year. Most were well-educated with at least a college degree. Children who visited the research toy exhibit tended to be 3-4 years old (mean=3.7 years; range: 1 to $8+$ years). When multiple children were present, age was coded as the oldest child in the group. Demographics of survey respondents were representative of the typical museum population.

Table 1. Demographic characteristics of survey respondents. 
A third researcher was stationed at the museum exit. Parents and caregivers identified as having visited the research exhibit via stickers were asked about their willingness to provide an email to participate in an online survey about guest experiences. Those who opted to participate were provided with two museum passes and entered into a raffle for a \$100 gift card once the survey was completed. To attenuate potential demand characteristics and direct associations with the research exhibit, researchers asking for parent emails wore a museum staff shirt.

\section{Survey}

We collected both qualitative and quantitative feedback from parents via a 41-question online survey. Parents were asked demographic questions and about their general experience at the museum and interest in child development research. In addition, targeted questions were asked about our research exhibit and a permanent museum exhibit to allow comparisons between the two types of exhibits. We confirmed participants had actually visited the exhibits of interest by presenting photographs of each exhibit and asking whether participants had visited that exhibit during their last trip to the museum. Three different permanent museum exhibits were available for potential use as the contrasting exhibit. These comparison exhibits were selected based on their popularity at the museum to maximize the likelihood that parents had visited them. These exhibits were presented one by one to parents at the start of the survey, and the first confirmed as having been visited was used for the comparison contrast.

Eight outcomes were examined. For the first five outcomes, parents responded on a 6-point Likert scale to the following questions about each exhibit: How much fun do you think your child(ren) had at this exhibit?; How interesting was this exhibit to you, as a parent?; Do you feel that - as a parent - you learned anything new from this exhibit?: Did this exhibit raise any questions for you about how people think or act?; and How relevant or personally meaningful was this exhibit to your everyday life as a parent? Likert responses were anchored with "Definitely did NOT [have fun, learning anything, etc.]" and "Definitely did [have fun, learn something, etc.]". All questions also provided an open text box to provide additional information about their responses.

For the three remaining outcomes, parents responded to yes/no questions about their experiences since visiting the museum: Since your visit, have you talked with anyone about something related to a Museum exhibit?; Since your visit, has anything that you have seen or done reminded you of this exhibit?; and Since your visit, have you applied ideas or information gained from this exhibit in your interactions with your child? Open text responses to the 
question asking about discussions related to the museum were coded for references to the research exhibit or comparison exhibit by the authors.

After completing questions on the research exhibit and one standing museum exhibit, the survey concluded. The survey was administered using SurveyMonkey (San Mateo, CA).

\section{Analytic Approach}

Within-person comparisons of responses to the research exhibit and comparison exhibit were conducted on eight outcomes described above. For ordinal outcomes, Wilcoxon signed-rank tests were used to test the null hypothesis that Likert responses to questions about the research exhibit and comparison exhibit were equivalent. For dichotomous outcomes, McNemar's chi-squared tests were used to test the null hypothesis that responses to yes/no survey questions about the research exhibit and comparison exhibit were equivalent. Responses of "not sure" and "don't know" were excluded for chi-square tests. All data, code, and materials can be found on the project's open science framework page (osf.io/g4kn8/).

\section{Results}

Overall, 72 individuals responded to the questionnaire. Missing data on individual items ranged from $2 \%$ to $40 \%$. Comparison museum exhibits included "Bubbles" ( $N=43$ ), "Kinetics" $(\mathrm{N}=15)$, and "Water" $(\mathrm{N}=2)$. Parent responses significantly differed on their ratings of learning something new between comparison exhibits $\left(F_{(2,56)}=3.876, p=.027\right)$. A follow-up Tukey's HSD test indicated that this difference was driven by parents reporting learning something new more on the "Kinetics" exhibit (Mean=3.73) compared with the "Bubbles" exhibit (Mean=2.74) $\left(p_{\text {adjusted }}=.034\right)$. Parent responses for all other questions did not significantly differ between permanent comparison exhibits. To test for differences between the research toy exhibit and permanent museum exhibits, all comparison exhibits were combined into a single "comparison" category for analysis.

\section{Comparisons Between Museum Exhibits}

Although parents indicated that their child(ren) had significantly more fun at the comparison exhibit relative to the research exhibit, parents themselves were significantly more likely to learn something new, have questions raised about how people think or act, and find relevance and personal meaning in everyday life in response to the research exhibit relative to the comparison exhibit (Table 2). 
Table 2. Responses to Likert-based questions about the research exhibit and comparison standard museum exhibit.

\begin{tabular}{|c|c|c|c|c|c|}
\hline & $\begin{array}{l}\text { Child(ren) } \\
\text { Fun }\end{array}$ & $\begin{array}{l}\text { Parent } \\
\text { Interest }\end{array}$ & $\begin{array}{l}\text { Parent Learned } \\
\text { Something New }\end{array}$ & $\begin{array}{c}\text { Raised } \\
\text { Questions } \\
\end{array}$ & $\begin{array}{c}\text { Parent } \\
\text { Relevance }\end{array}$ \\
\hline Research Exhibit & $4.38(1.37)$ & $4.81(1.22)$ & $4.15(1.66)$ & $4.18(1.51)$ & $4.78(1.41)$ \\
\hline Comparison Exhibit & $5.48(0.79)$ & $4.67(1.27)$ & $2.97(1.35)$ & $2.18(1.38)$ & $2.64(1.42)$ \\
\hline$p$-value & $<.001$ & 0.426 & $<.001$ & $<.001$ & $<.001$ \\
\hline $\mathrm{N}$ & 60 & 59 & 59 & 57 & 58 \\
\hline
\end{tabular}

Values are the means (SD). $p$-values reflect Wilcoxon signed-rank tests of paired differences.

The majority of parents (71\%) indicated that they found the research exhibit very interesting or extremely interesting (a 5 or 6 on the Likert scale). One parent reported: "I love that they were trying to educate the [g]uest on growth mindset. I find this topic so important in helping shape a growing child's mind. :)". Another parent stated: "I appreciated that the museum is sharing important research with parents." Another parent emphasized the lasting impact of the research exhibit: "The fact that I knew that the students were studying in college and it allowed me to elaborate on the experiment with my kids later. I love when I can continue discussions at home with my kids." These comments reinforce findings that parents were interested and appreciative of the research exhibit and that the impact of the research exhibit persisted following the museum visit. Parent interest in the standing museum exhibit appeared to be focused on children's learning and engagement rather than adult experiences: "I loved the different ways to make bubbles and measuring the bubbles."; "Just the way it is set up to engage the kids."; and "Watching how big the wall bubbles could get and seeing my son make his own bubbles with the tables and wands."

About half of parents reported that they definitely or almost definitely learned something new from the research exhibit (46.2\%) and that the research exhibit definitely or almost definitely raised questions for them about how people think or act (41.5\%). Parents' elaborations indicated that the research exhibit raised important questions about parent and adult behavior. For example, one parent noted: "The importance of how the simplest word dictated to a child can have a lasting impact on how he or she will take on a challenge." One parent noted that the research exhibit made them more aware of interactions with their children: "It made me more aware of what I praise my girls for (and others too ... other kids and even adults) and I would like to pay more attention to how other adults and teachers praise.". Another parent raised questions about how children will be praised by people other than their parents: "How do I praise our daughter? How can I best phrase my praise for her effort? Which types of praise will she receive at school, activities, etc. and how can respond?" 
Parents' elaborations on the standing museum exhibit focused on differences between children and the exhibit materials: "Made me think about just how different kids are when figuring out all of the different stations, how they work, what you can do, etc." and "How to increase the size of the bubbles at the table! And the part that has oxygen with it!"

Finally, most parents (69.8\%) found the research exhibit to be extremely relevant or meaningful to their everyday lives. Parent responses indicated that the research exhibit influenced their own behavior. For example, one parent stated: "I worry a lot about raising my girls with a positive attitude, hoping that they will be confident and adventurous and strong. I think that using more meaningful praise is a pretty easy step to take to get to those goals." Parents appreciated that the exhibit was meaningful to their lives: "Very much so! I feel not only children should develop growth mindsets but us adults too. It is so much more difficult for us to break out of our own egos at times. I must say my children have been my biggest teachers in re-learning this for myself." Another parent noted: "It helped me to think critically about how I respond to my children and the type of feedback I provide." For the comparison exhibit, parent responses focused on child exploration: "It's extremely important to me that my child always be curious and that she and I can have learning adventures together." and "It's always a helpful exhibit to encourage wondering."

\section{Experiences After the Museum Visit}

When reporting on their experiences since visiting the museum (Table 3), significantly more parents $(80 \%)$ had applied ideas or information gained from the research exhibit to interactions with their child(ren) or other than ideas or information gained from the permanent museum exhibit (14\% of parents). Significantly more parents also reported being reminded of the research exhibit than the museum exhibits (55\% of parents for the research exhibit; $25 \%$ of parents for the permanent exhibit). Parents did not significantly differ in discussing the research and museum exhibits with their children or others $(14 \%$ discussed the research exhibit; $21 \%$ discussed the permanent exhibit).

Table 3. Responses to dichotomous questions about experiences after the museum visit related to the research exhibit and comparison permanent museum exhibit.

Discussed the Exhibit with

Child/Others
Reminded of the

Exhibit
Applied Ideas from the Exhibit

\begin{tabular}{|c|c|c|c|c|c|c|}
\hline & Yes & No & Yes & No & Yes & No \\
\hline $\begin{array}{c}\text { Research } \\
\text { Exhibit }\end{array}$ & $7(13.5 \%)$ & 45 (86.5\%) & $29(54.7 \%)$ & $24(45.3 \%)$ & $43(79.6 \%)$ & $11(20.4 \%)$ \\
\hline
\end{tabular}




\begin{tabular}{|c|c|c|c|c|}
\hline $\begin{array}{c}\text { Standard } \\
\text { Museum Exhibit }\end{array}$ & $11(21.1 \%)$ & $12(25 \%)$ & 5 (13.9\%) & 31 (86.1\%) \\
\hline$x^{2}$ & 0.5 & 7.56 & & \\
\hline$p$-value & 0.48 & 0.006 & & 01 \\
\hline
\end{tabular}

Number of responses (percentages) are shown. $\mathrm{X}^{2}$ and $p$-values reflect McNemar's chi-squared tests of independence.

\section{Discussion}

This study was the first to demonstrate the impact of research exhibits on parents' learning and experiences at children's museums. Parents reported high overall interest in the research exhibit. Parents were more likely to learn something new, have questions raised about their behavior and others', and found the research exhibit more relevant to their everyday life compared with other permanent exhibits at the museum. Parents were also more likely to be reminded of and remember and apply what they learned at the research exhibit in their daily lives relative to permanent exhibits. This represents the first evidence that research exhibits provide unique benefits to museums and museum visitors relative to permanent museum exhibits.

Stimulating parents' interest and engagement in the science of child development through research-museum partnerships could lead to a multitude of downstream effects (Wood \& Wolf, 2008). Increasing parents' metacognitive awareness of children's learning processes could increase their effectiveness in facilitating learning opportunities, and as a result, children's learning (Thomas \& Anderson, 2013). Such effects could play out both in the museum and beyond. Appreciating the impact that exhibits may have on children's learning may lead to different parental behaviors in the museum itself (Knutson \& Crowley, 2005). For example, children learn more when parents discuss contents of museum exhibits with them after the visit and when parents find connections between museum exhibits and children's lives (Anderson et al., 2002; Benjamin et al., 2010; Haden, 2010). Engaging parents about child development could lead to increased engagement from parents while visiting the museum, as well as after the museum visit.

Our results could support future research-museum partnerships by demonstrating their value to stakeholders other than the researcher (Haden, 2010). Research exhibits provide parents with unique learning experiences at the museum that are not available through traditional permanent museum exhibits, which could thereby boost memberships and attendance. Such benefits may make museums more motivated to partner with researchers. The benefits of research exhibits relative to permanent exhibits documented here also represent a unique 
way in which research-museum partnerships serve the overall mission of museums to engage the communities they serve and improve public understanding of science.

Several caveats apply for generalizing our findings on the benefits of research exhibits for parents and parents in children's museums. First, the effects we report here could be driven in part by the specific research toy used, which focused on parent behavior, and also may not apply when research exhibits focus strictly on data collection or other research topics. Further, the research exhibit involved direct interaction with research staff, whereas the other comparison exhibits typically did not involve direct engagement with museum staff. Interactive interventions with permanent exhibits could show similar benefits. Because most parents reported a high level of education, they may have been more familiar with the concept of growth mindset or have more experience engaging with psychological research than other populations. However, our findings do indicate that parents willingly and meaningfully interact with scientists in museum settings. Although we attempted to mitigate demand characteristics, survey focus on the research exhibit and recruitment on only days in which the research exhibit was present could have influenced survey responses. Future studies can help to elucidate whether developmental research less relevant for parenting are similarly beneficial to museum visitors. Direct communication with research staff with parents could lead to greater parent interest in more permanent museum exhibits. Staffing more permanent museum exhibits could increase parent engagement at these exhibits, even when the exhibit themes are not directly related to parenting or child development. These possibilities, as well as their downstream impacts on child learning while at museums, should also be explored in future work.

Our findings support unique benefits of research exhibits beyond permanent museum exhibits. Researcher-museum partnerships can provide unique educational opportunities for museum visitors, which helps to serve a common aim of museums. Parents visiting the children's museum were a receptive audience for research staff and the research exhibit. These parents were very interested in learning opportunities not only for their children but also for themselves. When visiting the museum, parents were able to engage directly with scientific research and reported discussing and applying ideas they learned at the research exhibit in their daily lives after the museum visit. Our findings indicate that children's museums provide good settings to maximize the impact of research findings on child development by sharing developmental research with interested audiences. Showcasing potential learning opportunities for parents at research exhibits should be a priority for future research-museum partnerships. 


\section{References}

Anderson, D., Piscitelli, B., Weier, K., Everett, M., \& Tayler, C. (2002). Children's museum experiences: Identifying powerful mediators of learning. Curator: The Museum Journal, 45(3), 213-231. doi.org/10.1111/j.2151-6952.2002.tb00057.x

Beaumont, L., Todd, K., Pfeifle, S., \& Lindgren-Streicher, A. (2016). National Living Laboratory: Creating Communities of Learners for Informal Cognitive Science Education.

Benjamin, N., Haden, C. A., \& Wilkerson, E. (2010). Enhancing building, conversation, and learning through parent-child interactions in a children's museum. Developmental Psychology, 46(2), 502. doi.org/10.1037/a0017822

Bronfenbrenner, U. (1977). Toward an experimental ecology of human development. American Psychologist, 32(7), 513. doi.org/10.1037/0003-066x.32.7.513

Callanan, M. A. (2012). Conducting cognitive developmental research in museums: Theoretical issues and practical considerations. Journal of Cognition and Development, 13(2), 137-151. doi.org/10.1080/15248372.2012.666730

Callanan, M. A., Legare, C. H., Sobel, D. M., Jaeger, G. J., Letourneau, S., McHugh, S. R., ... \& Watson, J. (2020). Exploration, explanation, and parent-child interaction in museums. Monographs of the Society for Research in Child Development, 85(1), 7-137. doi.org/10.1111/mono.12412

Callanan, M., \& Valle, A. (2008). Co-constructing conceptual domains through family conversations and activities. Advances in Research and Theory, 147-165. doi.org/10.1016/s0079-7421(08)00004-2

Chandler-Campbell, I. L., Leech, K. A., \& Corriveau, K. H. (2020). Investigating science together: Inquiry-based training promotes scientific conversations in parent-child interactions. Frontiers in Psychology, 11, 1934. doi.org/10.3389/fpsyg.2020.01934

Corriveau, K. H., Kipling, R., Ronfard, S., Biarnes, M. C., Jeye, B. M., \& Harris, P. L. (2015). Living laboratory ${ }^{\circledR}$ : A mutual professional development model for museum-based research partnerships. Cognitive development in museum settings: Relating research and practice. New York: Routledge. 
Frank, M. C., Vul, E., \& Saxe, R. (2012). Measuring the development of social attention using free-viewing. Infancy, 17(4), 355-375. doi.org/10.1111/j.1532-7078.2011.00086.x

Gelman, S. A., Coley, J. D., Rosengren, K. S., Hartman, E., Pappas, A., \& Keil, F. C. (1998). Beyond labeling: The role of maternal input in the acquisition of richly structured categories. Monographs of the Society for Research in Child Development, i-157. doi.org/10.2307/1166211

Haden, C. A. (2010). Talking about science in museums. Child Development Perspectives, 4(1), 62-67. doi.org/10.1111/j.1750-8606.2009.00119.x

Henderson, T. Z., \& Atencio, D. J. (2007). Integration of play, learning, and experience: What museums afford young visitors. Early Childhood Education Journal, 35(3), 245-251. doi.org/10.1007/s10643-007-0208-1

Knutson, K., \& Crowley, K. (2005). Museum as learning laboratory: Developing and using a practical theory of informal learning. Hand to Hand, 18(4), 4-5.

Letourneau, S. M., Meisner, R., Neuwirth, J. L., \& Sobel, D. M. (2017). What do parents notice and value about how children learn through play in a children's museum?. Journal of Museum Education, 42(1), 87-98. doi.org/10.1080/10598650.2016.1260436

Lussenhop, C., Cahill, C., \& Lindgren-Streicher, A. (2013). National Living Lab Broad Implementation, Year 1: Creating Communities of Learners for Informal Cognitive Science Education Formative Evaluation Report. Museum of Science, Museum of Science, Boston. https://www.informalscience.org/national-living-lab-broad-implementation-year-1creating-communities-learners-informal-cognitive

Lussenhop, A., Mesiti, L. A., Cohn, E. S., Orsmond, G. I., Goss, J., Reich, C., ... \& LindgrenStreicher, A. (2016). Social participation of families with children with autism spectrum disorder in a science museum. Museums \& Social Issues, 11(2), 122-137. doi.org/10.1080/15596893.2016.1214806

Mueller, C. M., \& Dweck, C. S. (1998). Praise for intelligence can undermine children's motivation and performance. Journal of Personality and Social Psychology, 75(1), 33. doi.org/10.1037/0022-3514.75.1.33 
Rogoff, B. (2003). The cultural nature of human development. Oxford university press. doi.org/10.1037/e612832007-002

Sobel, D. M., \& Jipson, J. L. (Eds.). (2015). Cognitive development in museum settings: Relating research and practice. Routledge.

Thomas, G. P., \& Anderson, D. (2013). Parents' metacognitive knowledge: Influences on parent-child interactions in a science museum setting. Research in Science Education, 43(3), 1245-1265. doi.org/10.1007/s11165-012-9308-z

Tõugu, P., Marcus, M., Haden, C. A., \& Uttal, D. H. (2017). Connecting play experiences and engineering learning in a children's museum. Journal of Applied Developmental Psychology, 53, 10-19. doi.org/10.1016/j.appdev.2017.09.001

Willard, A. K., Busch, J. T., Cullum, K. A., Letourneau, S. M., Sobel, D. M., Callanan, M., \& Legare, C. H. (2019). Explain this, explore that: A study of parent-child interaction in a children's museum. Child Development, 90(5), e598-e617. doi.org/10.1111/cdev.13232

Williams, P. H., \& Sparks, J. (2011). Collaborative Inquiry at a Children's Museum: Benefits for Student Learning, Museum Outcomes, and Faculty Scholarship. Journal of Public Scholarship in Higher Education, 1, 31-46.

Wood, E., \& Wolf, B. (2008). Between the lines of engagement in museums: Indiana University and the Children's Museum of Indianapolis. Journal of Museum Education, 33(2), 121-130. doi.org/10.1080/10598650.2008.11510593 